\title{
Countering testimonial injustice: The spatial practices of school administrative clerks
}

\section{Abdullah Bayat}

School of Business and Finance, University of the Western Cape

abbayat@uwc.ac.za

https://orcid.org/0000-0002-1796-9526

\section{Aslam Fataar}

Department of Education Policy Studies, Stellenbosch University

afataar@sun.ac.za

https://orcid.org/0000-0002-6880-9223

(Received: 4 May 2018; accepted: 9 October 2018)

\begin{abstract}
In this article we discuss the phenomenon of how people's voices or opinions are taken up in relation to their professional status. We focus on administrative clerks in school contexts, people who occupy a professional category that is regarded as one of voicelessness and therefore easily ignored. Their low occupational role and status mean that their testimonies are deemed less credible than the testimonies of school principals and teachers. We refer to this situation as a form of testimonial injustice that is visited daily on these clerks. We illustrate how selected administrative clerks go about exercising their agency in the light of their experiences of such testimonial injustice and go on to establish a range of spatial practices that confer on them a credible professional status.

This article is based on a qualitative study of three administrative clerks in selected South African public schools undertaken over a 12-week period, followed up by further interviews and site observations. Combining the theoretical constructs of testimonial injustice and rhetorical space, we argue that the administrative clerks we studied engendered transformed rhetorical spaces, which are negotiated social spaces that allowed for their voices and opinions to challenge the testimonial injustice they experience. We suggest that they achieved these rhetorical spaces through their continual and active presence in their work environments. They engender rhetorical spaces in which their voices are deemed legitimate by forming close relationships with others in their work environments, enhancing their professional capacity by furthering their educational qualifications, and the successful accomplishment of additional role tasks. Our main argument is that these clerks, despite occupying a marginalised occupational status and suffering testimonial injustice, are able to exercise their reflexive agency to improve their credibility and thereby resist the testimonial injustice visited upon them.

This article contributes to nascent scholarship on school administrative clerks' contributions to their professional environments at their schools. We argue that their contribution is undergirded by spatial practices that can be understood partly as a type of resistance to their negative status and position at their respective schools. We suggest that while they are discursively projected as peripheral figures in their school environments, they nonetheless make valuable, yet under-valued, contributions to the functioning of their school.
\end{abstract}

Keywords: epistemic injustice, testimonial injustice, spatial practice, social justice, rhetorical spaces, school administrative clerks 


\section{Introduction}

Testimony is the exchange of information and knowledge between people who, by virtue of their interaction, establish a relationship. Testimony is given in a social space that is characterised by particular material and social dimensions. This social space has norms, which include rhetorical ones that govern who can speak and who listens to whom (Code, 1995). It is a familiar scenario in schools that when junior teachers, female staff members, or employees from minority groups voice an opinion or make a suggestion, not much attention is paid to them. Yet when a senior staff member or one with a higher position makes a similar suggestion, it is considered a good idea, and everybody listens. In this context the testimony of those occupying lower-ranking positions or belonging to marginalised social groups is dealt with by being rebuffed, doubted, and silenced. (Fricker, 2007). Wherever there is such an unequal normative social framework regulating the giving of testimony that of those who are disadvantaged by this system suffer what we call a type of testimonial injustice. This refers to the discrimination visited on the voices, opinions, and testimonies of members of marginal groups (Fricker, 2007).

In this article, we explore the everyday spatial practices of three school administrative clerks who, we aver, suffer testimonial injustice in their professional contexts. We aim to reveal how they exercise their agency through specific spatial practices that are enacted in their workplaces as a means of countering the testimonial injustice meted out to them by virtue of their subordinate positions.

Research indicates that marginalised individuals suffer significant testimonial injustice (Fricker, 2007) and that those who occupy secretarial and clerical positions routinely suffer this fate (Bayat, \& Fataar, 2018, Conley, Gould, \& Levine, 2010; Fearfull, Carter, Sy, \& Tinker, 2008; Thomson, Ellison , Byrom, \& Bulman, 2007). The marginalisation of administrative clerks is a result of the fact that public schools are largely bureaucratic organisations that place clerks at the bottom of the hierarchical order and regard clerical work as women's work (Fearfull et al., 2008). This hierarchy impacts negatively on the credibility of lower-ranked employees. Bureaucracy endows the holders of powerful positions such as those in management with greater credibility, while undervaluing the testimonies of those in lower marginalised positions. Wong (2003) explains that "marginalised groups typically tend not to be thought of as possessing much credibility" (p. 110).

We discuss, in this article, how school administrative clerks counter their marginal status. We argue that the qualitative findings from the study of three school administrative clerks in three public schools in Cape Town show that administrative clerks work actively to enhance their credibility and engender rhetorical spaces that afford them a voice in their schools; this, in turn, assists them significantly in setting up their professional practices in the school.

We based this article on a qualitative study of three administrative clerks, one male and two female, whom we purposively selected from a broader project on the identities and practices of school administrative clerks in public schools. They were chosen because of their lengthy 
tenure as administrative clerks at the primary schools where they are currently employed. They each completed a certificate in school business administration. We refer to them in this article as Pete, Meg, and Fay. ${ }^{1}$ The fieldwork included site visits to each school over a period of one school term (12 weeks), where we observed, interacted with, and interviewed the three administrative clerks. This was followed up by regular interviews over a period of a school year. We kept a fieldwork journal to gather observations. We also interviewed their principals, members of the teaching and non-teaching staff, parents on the school governing body (SGB), and educational district officials. One of the authors visited the schools once a week during the research period, spending a total of up to three hours per week at the three sites over the 12-week period. He observed and interacted with these clerks in their office spaces. We formally interviewed each of the three principals, and, in one case, one of the participant's previous principals, as well as at least one senior teacher and an SGB member per school. Informal conversations with teachers also took place during the research period.

The data was gathered in semi-structured interviews and through participant observation. We did not originally set out to investigate the voicing practices of these clerks or how their testimony was being received. Instead, we were interested in their identities and work practices. We were drawn to researching administrative clerks because of experiences and insights gained from a previous monitoring and evaluation (M\&E) project, in which one of us was involved, that investigated the training provided for administrative clerks. Through reflecting on the $M \& E$ project, we realised that the clerks were making a huge contribution to the school while remaining invisible. Fearfull et al. (2008) called this the "clerical conundrum" (p. 177), which refers to how the dominant discourse in organisations, at least in part, renders administrative clerks' contributions invisible.

Our research focus was initially broadly aimed at understanding the administrative clerks' professional practices in support of the administrative functioning of the school. We soon realised, as they were telling us their stories, that they were surreptitiously intent on getting us as researchers to delve beyond the surface appearances. We had to be virtuous listeners paying careful attention to the stories that were being related. As the interviews and observations progressed in their social spaces, our attempt to be virtuous listeners paid off. We began to notice that the administrative clerks were conveying to us how they were engaged in a complicated two-way interaction with the people, discourses, structures, and strictures of their schools. These interactions tended to render them invisible, but they nonetheless went about establishing practices to gain visibility and recognition. We struggled to make sense of this tussle. We employed an iterative research approach of moving between data and theory to illuminate the constitutive processes at play. Drawing on Lefebvre's (1991) work on social space, we suggest that their resistance to the testimonial injustice, enacted through a form of spatial practice enabled them to create a rhetorical space for themselves.

$1 \quad$ These are, of course, pseudonyms. 


\section{Theoretical considerations}

Our theoretical approach here is based on a consideration of testimony as a spatial practice combined with the notion of rhetorical space, which allows for understanding how testimony, as an act of agency, has consequences for how social space is shaped and reshaped.

Testimony is the core vehicle through which people communicate. Testimony is broadly defined as "any kind of telling in and through which the expression and transmission of knowledge becomes possible" (Medina, 2012, p. 28). Such testimony or telling, if expressed in a manner unencumbered by social position or status constraints, enables the expression of agency. In contrast, as Fricker (2007) has explained, testimonial injustice refers to a situation in which a person's testimony is ignored because of her or his marginalised social location, occupation, or identity. The testimony of a person is dismissed because of prejudice on the part of the hearer. She has argued that "testimonial injustice is a normal part of discursive life" (p. 39) for those who have their testimonies routinely dismissed and devalued as a consequence of their marginalised status. Testimonial injustices take place "when speakers suffer credibility deficits due to identity prejudices on the part of their hearers" (Maitra, 2010, p. 196, emphases in original). Persons who are identified as socially marginal, such as the administrative clerks discussed below, experience plummeting credibility irrespective of the veracity of their testimony.

Testimonial injustice occurs when the listener does not make sure that his or her judgment about credibility takes into account the veracity of the evidence and not only the social position of the speaker. When this occurs, the testimony of those with less social prestige enjoys less credibility. Fricker (2007) suggested that otherwise credible informants may end up being ignored because they have been identified with a subjugated social group. Thus, worthy informants are denied an opportunity to participate in the transmission of knowledge and the hearer misses out on an opportunity to benefit from their testimony. For example, the worthwhile testimony of an administrative clerk might be overlooked because of her or his low occupational role and the social status associated with this position, while a school's principal and senior teachers are granted credibility by virtue of their higher occupational status.

Based on the view that space is thoroughly social (Lefebvre, 1991), we contend that giving testimony is entangled in space and is constitutive of space. Space is not an empty background, but a constitutive part of an administrative clerk's social world and workplace. Social space shapes the manner in which testimonial injustice occurs as well as the way in which it can be resisted. Lefebvre (1991) argued that social space is produced through three dialectically interconnected processes. He calls this a spatial triad which includes spatial practices, representations of space, and spaces of representation. Lefebvre (1991) from a phenomenological perspective, also labelled this spatial triad perceived, conceived, and lived space, respectively. Schmid, (2008) explained that perceived space is what the body materially encounters, conceived space is how those in power ideologically and institutionally frame space, and lived space is how individuals' experiences space 
symbolically. The spatial triad is constitutive of all spaces. All three processes of spatial production occur simultaneously in everyday interaction. In other words, it is the particular interaction between and among these three spaces that produces social practices. An analysis of social space depends on a relational reading of the specific articulation of the spatial triad, in our case, the social practices of giving testimony, institutional norms concerning testimony and knowledge, and the symbolic and imaginative dimension of administrative clerks' testimonies in their work sites.

In the context of the article the representations of space or conceived space structure administrative clerks' decisions about how to operate in and make sense of their space. Conceived space provides the rules that govern the office space. These rules are embedded in the school's discourses and include the occupational role that administrative clerks are supposed to play at school, as well as the requirement that administrative clerks comply with the directives of their principals and the teachers. Emphasising the rules of dominant actors, conceived space refers to the rhetorical rules and restrictions placed on the clerks' testimony and practices, while also providing them with certain rhetorical allowances. The rules and restrictions circumscribe the clerks' communicative influence in their workplace.

Perceived space refers to what the administrative clerks grasp through their senses, including seeing, feeling, and hearing. Spatial practices refer to the activities and interactions as they occur in a particular space. Both perceived space and spatial practices thus describe the social-material dimension of space. Giving testimony is a spatial practice so testimonial communicative events are spatial practices of school administrative clerks. Administrative clerks understand their perceived space as the way in which their principals and teachers, students, parents, and district officials interact and communicate with them every day in their office space. The identity prejudices and credibility deficits that some school staff have toward administrative clerks are woven into the fabric of school spaces. The clerks sense the responses of the principal and teachers to their testimony sometimes as an affirmation but at most times a repudiation of their testimony and worthiness. The administrative clerks' perception of how their testimony is dealt with by the school staff forms and fashions their notion of their perceived space and what spatial practices are acceptable. Normative spatial practices are maintained, both through the organisational systems and through the informal aspects of the school's culture and context.

The third element in the triad, spaces of representation or lived space, refers to the administrative clerks' desire, affective experiences, and imagined potentiality, all of which they may incorporate into their spatial practices. This is the space of enablement or lived agency, where, in interaction with perceived and conceived space, the agent establishes viable social practices through a range of tactics, positionings, and testimonial deployments (De Certeau, 1984). This is an active space of agency acquisition and assertion.

Linking the giving of testimony to social space, we draw on the concept of rhetorical space; it emphasises the ways in which space limits and shapes all that can and will be "heard, understood, [and] taken seriously" (Code, 1995, p. ix-x) within that space. Testimonies are given in rhetorical spaces that are constructed through a specific articulation of the spatial 
triad. When an administrative clerk gives testimony, this takes place within a particular social space, i.e. a particular rhetorical space. Rhetorical spaces are social spaces in which there are particular forms of structuring that determine who may speak and how, and which language regime or discursive register is in use. Code (1995) explains rhetorical spaces as

fictive but not fanciful locations whose (tacit, rarely spoken) territorial imperatives structure ... and limit the kinds of utterances that can be voiced within them . . an expectation of being heard, understood, taken seriously. (p. 12)

Each rhetorical space in the school has its own imperatives and constraints that arise from how the space has been conceived, perceived, and lived by the administrative clerks. Although all three spatial dimensions influence the nature of the rhetorical space open to the school administrative clerks, it is their lived space that we wish to explore. Notwithstanding our focus on lived space, the dialectical nature of the spatial triad means that we need to engage with all its dimensions.

An emphasis on the lived dimension of rhetorical space allows us to observe the agency of administrative clerks as they deal with the attitudes of school staff, whether stereotypical and prejudicial or accepting, toward their testimony. Agency is entangled in lived space and becomes manifest in the reshaping of rhetorical spaces in the school context. By positing that space is produced in everyday interaction, we are suggesting that through their spatial practices school administrative clerks rework and adjust the school's existent rhetorical space. The clerks are in part able to transform their subordinate spatial positions and work with the materiality of their work spaces to establish themselves as empowered agents.

This theoretical frame provides a lens through which to view administrative clerks' testimonies. Regarding the giving of testimony as a spatial practice can inform us about how administrative clerks' testimonies are received in their schools. If administrative clerks are suffering testimonial injustice, their spatial practices, as instances of agency, can show us how they carefully craft and carve out transformed rhetorical spaces in order to give testimony. Their spatial practices assist us to see how structured school social spaces can simultaneously also be sites of administrative clerks' agency and resistance. In their lived space administrative clerks imagine the school as a space where their testimonies are heard, and social practices established.

\section{Contextualising the testimonial practices of the three school administrative clerks}

The discussion here provides a contextual backdrop against which the administrative clerks' testimonial practices can be viewed and understood. Administrative clerks in the Western Cape tend, in general, to have lower educational qualifications compared to the teachers and principals at their schools (see Naicker, Combrinck, \& Bayat, 2012). The typical administrative clerk has a matric certificate (Grade 12) and administrative experience (see Naicker, Combrinck, \& Bayat, 2011) and, even if they have a post-matric qualification, it is 
not likely to be in education-related areas. School administrative clerks are designated as nonteaching staff and this, combined with their low occupational status, leads to an identity deficit that confers on them a subordinate occupational status at their school.

\section{Introducing the participants in the study}

Meg has worked at her school since 1999. The school is in a poor, previously white area that has experienced a dwindling white population. Meg grew up and lived in the area, attended this school as a student, and worked previously as a secretary for a local medical doctor. She is currently the school's only administrative clerk and has a formal yet close relationship with the principal. He runs the school in a top-down manner in a strict and controlling leadership style. Meg is a member of the school governing body (SGB) but is not part of the school management team (SMT). She is engaged actively in the affairs of the SGB, where her opinions do have some resonance. Meg has a certificate in school business administration. She graduated as the top student in her certificate course and was honoured as such at her college graduation.

Meg is supportive in her interaction with students and parents. She keeps abreast of developments and changes in the students' families. She knows whose parents have divorced and who is looking after the children when the parents are at work. Having grown up in the area, the length of her service has given her insight into the social dynamics of the students and their families. Thus, she has a nuanced understanding of what is happening in the lives of many of the students. If, for example, a student is acting up in class, she might have information that could help the teacher deal with that student. She uses the SGB as a rhetorical space in which she voices her opinions.

Pete is employed at a primary school that is situated in a black township. The students who attend the school are impoverished. Pete lives in this township and his son attends the school. As a male, he is atypical of administrative clerks in the Western Cape. He is an active community member and leader. He started working at the school soon after it was established in 2001. Pete is the more senior of the two school administrative clerks at his school and is currently a member of the SMT and the SGB in which he serves as the financial officer. Pete has an honours degree and is currently doing his master's degree in public administration at a local university. Pete also holds a certificate in school business administration. His involvement in local community issues gives him a deep contextual understanding of the students and teachers from the area.

Fay has been an administrative clerk since 1997. She has been at her current school, which is situated in a working-class coloured area, since 2002. Fay grew up in a similar community. She is one of two school administrative clerks. She handles the finances and heads the fundraising committee. Fay completed an adult basic education and training diploma course and has been teaching adults at a local school. She is currently registered for a teaching degree through a distance-learning university. She is a member of the SGB and had previously attended SMT meetings. Her knowledge of finances and fundraising raises her 
testimonial profile at school and makes her testimony credible in this domain. This extends to the SGB and to the time during which she participated in meetings of the SMT.

The office space of an administrative clerk is designed to accommodate a support and nonteaching staff member. It is not conceived of as a management, teaching, or learning space. These limitations affect the rhetorical situation of the administrative clerks. However, the administrative clerks' experiences have provided them with insight and understanding of teaching and learning matters, school management, and community affairs.

\section{Valuable testimony: The contextual knowledge of administrative clerks}

Administrative clerks have unique perspectives, insights, and situated knowledge, all of which are the result of their spatial practices at school (Harding, 2004; Nonaka \& Toyama, 2003). The creation and dissemination of testimony involves situated human beings whose experiences and understanding are shaped by the social interactions and relationships that permeate their social positioning in particular spaces. The three administrative clerks have had many years of building relationships in their respective schools. Their spatial position in the school office gives them insight into the daily social functioning and activities of the school that might not be available to those in more elevated positions, such as the teachers and principals.

We observed that the administrative clerks interact with students and parents in ways that the teachers do not. For example, a learner or parent will provide administrative clerk with details of their personal lives. This often happens in cases where they do not feel comfortable communicating with the teacher(s) so the clerks often have access to personal information to which teachers do not, so they gain the trust of the students. They interact with parents and students when the parents enrol their children, when they come to pay fees, and purchase uniforms, and they interact with students when they deliver messages from their teachers. Students also interact with the administrative clerk when they are given messages from parents who have phoned the clerk, or when students need medical attention, or the clerks provide mediation when students are involved in an altercation.

The administrative clerks' situated knowledge and perspectives are an important resource for teachers and principals. For example, administrative clerks would know which students have not paid fees and in some cases the reasons for non-payment and, at times, they are privy to the private troubles students suffer at school or at home.

Administrative clerks have experience and training in school administration and management from which the teachers and the principals benefit (Rimer, 1984). From our observations and interviews it became evident to us that, even without formal teacher training, they used their accumulated contextual knowledge to engage in practices that enhance students' social and moral development. A particular example we witnessed was Meg's being called on to arbitrate between two students who had been fighting in the playground. She listened to each of the students as they explained their actions and then proceeded to guide them toward resolving their differences. 
The administrative clerks acquire anecdotal information from various sources, such as students, parents, social workers, and educational officials. The school administrative clerks in this study could therefore be regarded as situated knowers whose testimonies hold value for their schools' administrative functioning in addition to their educational effectiveness. Yet, as we go on to show, in spite of all this, their testimonies are listened to selectively and often simply ignored or overlooked.

\section{Experiencing testimonial injustice in rhetorical spaces}

In this section we lay out a synopsis of the administrative clerks' rhetorical space. We then go on to draw attention to nuanced incidents of testimonial injustice that the school administrative clerks experienced that reflect the different spatial contexts within which they work.

The conceived space of the administrative clerks is constrained by the regulative discourses in their institution. They have to obey and defer to the principal, they have to know their place. They are expected to transact their spatial practices in accordance with the hierarchical order of administrative clerks' conceived space. We provide evidence of this below. This dimension of space has an impact on how the principal and teachers listen to, hear, and mishear the administrative clerk. This spatial articulation carries within it limited potential for administrative clerks' voicing practices. The clerks often perceive this limitation as frustrating and a negation of their potential to make a multidimensional contribution to the school.

Venting his frustration at not being heard by the principal, Pete explains that "it seems. . . whatever we [referring to himself] say doesn't make sense to him [the principal]." Here Pete seems to be offering an excuse for the principal who refuses to listen to, and engage with, the implications of Pete's testimony. In other comments Pete noted that his suggestions were for the most part not acted upon by the principal. It seems to us that his diminished status renders his opinions less believable in the rhetorical space of the principal's office.

Meg explains how the teachers and the principal do not acknowledge her testimony. She said, "But I'd say to them . . . but it does not register." She attempted to converse with them about "certain kids" (who are problematic for teachers) but her cries were ignored. Meg said,

... teachers and with the principals, they're very hard on certain kids and I know what their circumstances are so I tend to be soft with them, and they will come to me, they'll actually come into my office . . . but I'd say to them [the teachers], 'But you know what, what's going on at home?' But it doesn't register [with the teachers], I suppose they have to be the disciplinarian.

Fay commented on her frustration about being asked for her opinion, but then having her testimony ignored. She told us that her testimony was solicited on a particular occasion but when the principal spoke to someone else (a teacher), he set her testimony aside. He had allowed her to expand her rhetorical lived space to advise him, but then retracted and 
restricted it and further devalued her testimony in relation to the teacher's testimony. Fay said,

Sometimes he [the principal] will come to me for advice, then I will tell him, 'okay this', then he will go, then he talks to that person, then he rather . . . my thing is this, why did you come to me in the first place? ... I want to put in my input and it's not . . . welcomed.

Her comments indicate that the principal occasionally gave her an opportunity to voice her opinion, but that he considered it of lower value compared to the opinions of the teachers. It would thus seem that the principal wants to solicit her testimony, but when it conflicts with, or differs from, the views of more highly placed individuals, such as teachers, it is disregarded.

Furthermore, Fay found that when she presented the budget at the SGB meeting at the beginning of the school year, she received negative comments from some of the senior teachers. She felt that they were questioning her credibility in terms of being qualified to discuss the budget. She felt that those teachers did not consider her testimony credible because she was an administrative clerk. According to her, "They did not question the worth of my work, but rather they questioned my worth." She seemed to imply in one of her interviews that teachers might be jealous of her because of her knowledge of the school's financial matters. Fay commented that the teachers think that she is beneath them, that they think that (she) is only a secretary: "Jy is maar net " $n$ secretary" [You are only a secretary].

From the above discussion we can infer that administrative clerks are subjected to testimonial injustice. The conceived space for administrative clerks' testimony is restrictive. They interact every day in a constricted rhetorical space, speaking even though they are not heard. Their affective experience of providing testimony is one of rejection, being belittled, and having their testimony ignored.

However, as we will show below, their lived encounters in their workspaces are not closed off to meaningful social practices informed by agency. Their lived space is where they imagine themselves being accepted, respected, and credible. Testimonial injustice is a part of their schools' conceived and perceived space, but in their lived space they envisage and imagine a greater testimonial role for themselves. Their lived space is framed by the hope of being heard. In the following sections we discuss some of the administrative clerks' spatial practices undertaken in their struggle to be heard.

\section{Striving for credibility: Engendering reworked rhetorical spaces}

In the previous section we demonstrated the testimonial injustice that these administrative clerks suffered and the limited rhetorical space they enjoyed at their schools. In this section, we discuss the spatial practices through which they found gaps in their school spaces in 
which to counter this epistemic injustice. Four spatial practices are considered: their presence in their work spaces, forming close relationships, credibility enhancement through further study, and taking on extra-role work. We argue that it is through these spatial practices that the administrative clerks succeeded in enhancing their testimonial credibility.

\section{Spatial participation}

The issue of their continuity of spatial presence refers to the administrative clerks being physically present and actively participating in the rhetorical spaces that their school spaces offered. Their physical presence in the front office of the school is a job requirement. However, it requires the administrative clerks' agency to activate their physical presence and turn it into a spatial practice to build credibility. It was their desire to play a meaningful role and be recognised as more than just administrative clerks that motivated them.

In terms of their strategy of spatial participation, the selected administrative clerks strove to remain rhetorically involved in many forums and spaces within their schools. This included being part of the SMT (Pete and Fay at particular times), the SGB (all three administrative clerks) and sub-committees of the SGB, particularly the finance and the fundraising committees. Attending SMT meetings was not an expected requirement for the clerks, but they all requested access to this social space from time to time. They did not restrict themselves to the behavioural limits placed on them by the regulative discourses of the SGB and SMTs. As they cautiously exercised their agency, they found that gradually their testimonies were being noted. The three administrative clerks indicated that it was a steady but fraught and inconsistent process, with advances and retreats that gradually led to the production of a more just and inclusive rhetorical space at school. Once they had negotiated a more inclusive space, the administrative clerks found fertile ground for their testimonial contribution.

One of the teachers interviewed acknowledged Pete's credibility when she said, "Even ... when there's [a] parents' meeting, he [is] the one who is able to convince and talk about the problems . . . and bring good suggestions." In addition, the deputy principal commented on how Pete had enhanced his credibility with school governors by explaining that

Pete was the one who is always on the school premises, he knows what is happening and he would be the one who tells the governing body what is really happening. If the governing body sometimes is resisting, he will then intervene . . because he is always at [school], he knows what is going on inside the school, you know.

The clerks' spatial participation is facilitated by their being in their offices to answer the phone, welcome guests, and deal with queries from the education department officials, teachers, parents, etc. This allows them to acquire an in-depth perspective on events and issues that involve the school. Their spatial participation also means they are the first at school and probably the last to leave. Whenever teachers had an administrative query, they tended to turn to the administrative clerks for assistance. 
Meg's principal has come to rely on her testimony to reflect on his decision-making and to aid him in making further decisions. Meg illustrated the dynamics of the morning conversations between her and the principal.

So we got about ten minutes between 5 past 7 and quarter past 7 that we'll chat about the day ahead or yesterday. . . but we do have that informal meeting. . . He either comes to chat to me here or I go to his office. He'll tell me what he's worried about, this is going to happen today, he'll tell me if he is going to be out for a while. . .

Meg said that the principal used these informal chats to solicit her opinion on some of the issues that needed to be addressed. Their regular conversations (they had been working together since 1999) based on her presence at school meant that she had opportunities to slowly chip away at the principal's dismissive attitude toward her testimony. She indicated that she had over time manged to build up her credibility with the principal.

The clerks' spatial participation afforded them situated knowledge which they used to enhance their credibility. Fay recounted many occasions in which one of her previous principals would step into her office and ask her about the background and request advice concerning an issue before making a decision. This action by the principal underscored the testimonial credibility that she had gained with him because of her presence at school.

\section{Forming close relationships}

Cultivating and maintaining relationships is a key spatial practice through which the clerks improved their credibility. The dialogical nature of school social spaces means that these spaces are sites of contestation and negotiation. Administrative clerks courted relationships with school staff to enhance their credibility. Pete cultivated a close relationship with the principal, deputy principal, and some of the heads of departments. He recounted many conversations that he had with the principal about how to improve the school. For example, he addressed the principal at the end of the school year about implementing strategies to improve the school's low annual national assessment scores. The principal agreed that he would launch a plan the following year to improve the implementation of the curriculum, which, according to the principal, was informed by some of Pete's "sensible practical advice."

Describing his interaction and communication with the principal, Pete explained,

I approached Mr S [the principal] and tell him about my concerns . . because normally when I talk to him, I wouldn't say 'Mr S, can I have a minute because I have a concern.' I normally would communicate, maybe hijacking the conversations that we made and then comment about a certain thing.

In this way Pete injected his testimony into the existing conversation. We suggest that this was possible because he had built a close relationship with the principal. 
Pete said that he developed a relationship with a former principal, who is now a local educational district official, and that this man had come to respect Pete's opinion. He said that this official came to him recently and said, "Pete, you are the person, I trust your opinion." Pete explained that this official also said he had trusted him (Pete) to "“always have a neutral opinion." Pete pointed out that "he asked me . . . he used to give me a scenario and then ... ask my opinion around that and I normally give my opinion.” Such trust, we posit, was built through friendship and a close bond.

Meg formed close relationships with certain teachers and the principal. Thus, the principal felt he could in some instances trust her voice and testimony and ask her for advice. The principal said about Meg, that "if I ask her for . . . advice, she will give it." This, we suggest, indicates that her testimony had become more credible.

Fay also established a close relationship with one of her previous principals with whom she enjoyed an enhanced testimonial credibility. She said,

He could see where I'm coming from, we were talking out of each other's hand . . if I say ' $\mathrm{Mr} \mathrm{V}$ what do think of this? Juffrou, ons maak dit soos jy sê (Miss, we will do it as you say).

By building an affable and gracious relationship, she persuaded the principal to give greater credence to her testimony. At the same time, she remarked that this principal signalled to her the extent to which he was extending her credibility by commenting in playful language, " $J y$ sê nie iets vir my nie, hoor" (You don't tell me anything, you hear me.). This shows that although her testimony had enhanced credibility, he was alerting her to be mindful of the diminished testimonial status of the clerical role.

During an interview with this previous principal, he acknowledged that he had had a close working relationship with Fay. There is a spatial dimension that underpins close relationships. The proximity in which the principal and the administrative clerks work promotes mutual understanding and respect. All three of the administrative clerks in this study developed close relationships with their principals and certain teachers through working closely with them over many years and gaining their trust. They also developed working relationships with many service providers, community nurses, parents, and educational authority officials across the educational environment with whom they enjoyed testimonial credibility.

Through these relationships administrative clerks enhanced their credibility with the staff at the school level and with the educational authorities at the district level. It is therefore clear that their circumscribed agency notwithstanding, the administrative clerks re-positioned their testimonies, knowledge sharing, and other practices to meaningfully contribute to their schools' daily operations. 


\section{Enhancing their credibility through academic credentialing}

The testimonial injustice that administrative clerks experienced is related to their lack of social power. Thus, in order to increase their credibility, the administrative clerks increased their human and social capital. All three administrative clerks embarked on improving their academic credentials, which involved completing the specialised Certificate in School Business Administration (CSBA) training course. All three administrative clerks commented that this had enhanced their understanding of school governance and school management, which enhanced, in turn, their capacity for acquiring agency in these domains. They did further training and two of them are currently pursuing academic degrees at local universities.

Pete explained that "if people [the teachers and principal] are aware that you are a master's student they will tend to listen to what you are saying." Meg said, "It [my credibility after doing the CSBA] has [improved] a lot with $\mathrm{Mr} \mathrm{K}$ [the principal] . . . and the . . . new governing body as well." She also said that the principal now introduces her to a new parent with words such as, "This is the school business manager."

Through increasing their educational credentials, the administrative clerks enhanced their credibility, which enhanced their authority and gained some newfound respect for their opinions. Academic credentialing therefore played a key role in enhancing their testimonial credibility.

\section{Fostering credibility through additional role tasks}

Another spatial practice through which the administrative clerks fostered their credibility was by constantly doing additional role tasks and doing them successfully. Even though they were sometimes subtly coerced into doing these extra role tasks, they used the successful execution of these tasks to build credibility in the school. This included doing some of the principal's and the teachers' work, attending after-school functions and events and being part of the various sub-committees of the SGB.

Commenting on how she goes along with the subordinate position assigned to her to do extra role tasks, Meg said, "You do your daily tasks, things that Mr K would ask me to do that I would fit in, things that the teachers ask me to do, I would fit in then." She explained that the more successful she became at these extra-role tasks, the more her credibility increased: "As I got more responsibility, I got more respect as everything went smoothly."

Pete also commented that he was successfully doing some of the principal's work. We consider this an important reason why he was able to gain credibility with his current principal. He said, "I'm doing the administration that is supposed to be done by the principal." The deputy principal at Pete's school commented on Pete's commitment to the school when she said,

Pete is really doing a good job. He's sometimes assisting the principal writing the minutes for the SGB you know. Pete is good in keeping the finances and when you ask Pete to do something for you, he's willing to do that, he's always willing. 
These and similar statements bear testimony to Pete's enhanced status and credibility at school.

In sum, the administrative clerks exercised their agency to counter the stigma of their subordinate social position. They engaged in novel spatial practices, imagined new lived spaces, and tried to influence the conceived space notions of those around them to get their voices heard. Being on the SGB and SMT were important spatial practices during which the administrative clerks strove to make their voices heard. Even though there is recognition of the administrative clerks' contribution, it remains a struggle for them to challenge their placement in the school's hierarchy. Notwithstanding the praise lavished on them by teachers and principals, this does not change the marginality of their occupational position.

The three administrative clerks were able to imagine a different lived space and engaged in spatial practices that reflected their agency. They established spatial practices that enhanced their credibility. They reflexively employed their agency to change the perceptions of their testimonial competency among their principals and teachers. They engaged in sustained spatial practices_actually, acts of resistance — that enhanced their credibility.

The clerks' spatial practices of active spatial participation, cultivating close relationships, doing praiseworthy additional role tasks, and increasing their human capital through further study were deployed to engender an expanded rhetorical school space. We have argued that the administrative clerks engendered spatial practices through which they were able not only to express their opinions, but also to have these opinions regarded as credible and worthy. By countering the testimonial injustices to which they were subjected, the administrative clerks were able to counter the prejudiced stereotypes held by their hearers.

\section{Conclusion}

Our task in this article is aligned with Fricker's (2007) contention that the testimonies of marginalised individuals, such as administrative clerks, are ignored and overlooked. The bureaucracy and hierarchical structure of public schools tend to limit the testimonial credibility of administrative clerks. Prevailing educational management discourses confer limited testimonial credibility on their professional status. Their office spaces, where they are based, have limited rhetorical prospects. Thus, administrative clerks are restricted from having their testimony heard, understood, and believed, even when it contributes meaningfully to their schools' operations.

Given these restrictions, we show that the three school administrative clerks exercised their agency through establishing alternative spatial practices. They engendered rhetorical spaces in which their testimonies enjoyed enhanced credibility. Through their spatial practices they provided their testimonies in selected rhetorical spaces, despite being subjected to testimonial injustice. These practices show them to be impactful contributors to their school's daily functioning. Through these spatial practices they resist the epistemic injustices of their occupational position. 
We have demonstrated not only how testimonial injustices are perpetuated, but also how they are resisted. We have shown that, despite the spatial constrictions that confront the clerks in their school work spaces, they have strategically and deliberatively fashioned rhetorical spaces that conferred on them the testimonial credibility that allows them to play a meaningful role in their work environments. The three administrative clerks wanted to be heard and recognised for their contribution to their schools, and to this end they reflexively went about building credibility, which emerged as a result of prudently engaging in sustained micro-spatial practices. These spatial practices included their spatial participation, close relationships with significant others at the school, furthering their academic qualifications, and performing additional role tasks successfully and competently. We have argued that subordinate groups, such as the school administrative clerks discussed here, engage in credibility-bolstering exercises by which they enhance their standing and integrity within their specific local contexts and, in doing so, change the lived nature of their work spaces. Their practices are ideologically and discursively invisible, yet they contribute immensely to the institutional practices of the school by countering the testimonial injustice visited upon them as a consequence of their occupational position. They are nevertheless caught in the duality of being discursively invisible while being practically impactful.

\section{Acknowledgements}

The authors wish to thank the National Research Foundation (Thuthuka) for providing funding for the research which was conducted as part of the first author's PhD research. This article draws on a seminar presentation on the topic of this article by the first author at Manchester Metropolitan University, United Kingdom. The authors would like to thank the seminar participants and the two blind reviewers of this article for their comments.

\section{References}

Bayat, A., \& Fataar, A. (2018). Beyond clerical support: School administrative clerks' ethical contribution to the professional functioning of their schools. Iranian Journal of Comparative Education, 1(1), 92-119.

De Certeau, M. (1984). The practice of everyday life. Berkeley, CA: University of California Press.

Code, L. (1995). Rhetorical spaces: Essays on gendered locations. New York, NY: Routledge.

Conley, S., Gould, J., \& Levine, H. (2010). Support personnel in schools: Characteristics and importance. Journal of Educational Administration, 48(3), 309-326.

Fearfull, A., Carter, C., Sy, A., \& Tinker, T. (2008). Invisible influence, tangible trap: The clerical conundrum. Critical Perspectives on Accounting,19(8), 1177-1196. 
Fricker, M. (2007). Epistemic injustice: Power and the ethics of knowing. New York, NY: Oxford University Press.

Harding, S. G. (2004). The feminist standpoint theory reader: Intellectual and political controversies. New York, NY: Routledge.

Lefebvre, H. (1991). The production of space. Oxford, UK: Blackwell.

Maitra, I. (2010). The nature of epistemic injustice. Philosophical Books, 51(4), 195-211.

Medina, J. (2012). The epistemology of resistance: Gender and racial oppression, epistemic injustice, and resistant imaginations. Oxford, UK: Oxford University Press.

Naicker, V., Combrinck, T., \& Bayat, A. (2011). An evaluation of the present status of the certificate in school business management. African Journal of Business Management, 5(15): 6434-6442.

Naicker, V., Combrinck, T., \& Bayat, A. (2012). Review of the current status of the pilot certificate in School Business Administration (CSBA) 2008-2009: Guidelines for CSBA 2010. Bellville, RSA: University of the Western Cape, School of Business and Finance.

Nonaka, I. \& Toyama, R. (2003). The knowledge-creating theory revisited: Knowledge creation as a synthesizing process. Knowledge Management Research \& Practice, l(1), 2-10.

Rimer, A. (1984). Elementary school secretary: Informal decision maker. Educational Horizons, 63(1), 16-18.

Schmid, C. (2008). Henri Lefebvre's theory of the production of space: Towards a threedimensional dialectic. In K. Goonewardena, S. Kipfer, R. Milgrom, \& C. Schmid (Eds.), Space, difference, everyday life: Reading Henri Lefebvre (pp. 27-45). New York, NY: Routledge.

Thomson, P., Ellison, L., Byrom, T., \& Bulman, D. (2007). Invisible labour: Home-school relations and the front office. Gender and Education, 19(2), 141-158.

Wong, J. (2003). Can power produce knowledge? Reconsidering the relationship of power to knowledge. The Southern Journal of Philosophy, 41(1): 105-123. 